\title{
EMPOWERING STUDENTS TO BECOME EFFECTIVE LEARNERS THROUGH ACTIVITY BASED LEARNING
}

\author{
Dr. S. Kanchana ${ }^{1^{*}}$, Dr. S. Patchainayagi ${ }^{2}$, Dr. S. Rajkumar ${ }^{3}$ \\ ${ }^{1}$ Assistant Professor, Department of Computer Science, PSG College of Arts \& Science, Coimbatore, India, ${ }^{2}$ Assistant \\ professor, School of Advanced Sciences, Vellore Institute of Technology, Chennai, India, ${ }^{3}$ Assistant Professor, Department \\ of Mechanical Engineering, Institute of Technology, Hawassa University, Awassa, Ethiopia. \\ Email: *kanchana.arun@gmail.com
}

Article History: Received on $18^{\text {th }}$ May 2019, Revised on $27^{\text {th }}$ August 2019, Published on $18^{\text {th }}$ September 2019

\begin{abstract}
Purpose of the study: Activity based learning helps students to learn actively in classroom and it also provides ample scope for experimental learning. Students are to be provided opportunities and optimum learning environment to explore their knowledge and skills. It would broaden the understanding of concepts and theories in their core premises. It enhances the learning process and the students as active learners.
\end{abstract}

Methodology: Interactive learning strategies are categorized as individual learning and group learning strategies. Individual activities may include flipped learning, polling answers and questions. Group activities include pair and share strategy, inspire and initiate scenarios.

Main Findings: Interactive learning strategies, E-Learning and M-Learning are preferred modes for the students, promotes the cognitive level of the learners, achieved learning objectives. It is essential to suggest and design innovative learning practices.

Implications: Higher education institutions and even schools are using various enhanced interactive learning practices, educational apps and M-Learning techniques. These activities enhance the student engagement in the classroom. By implementing activity based learning practices, learners become investigators and strive to make best real time decisions for different scenarios.

Novelty/Originality of this study: Enhanced learning strategies promotes cooperative learning and efficient for large group of learners.

Keywords: Activity based learning, Empowering students, Active Learners, Flipped learning, Innovative learning practices, M-Learning.

\section{INTRODUCTION}

"Education is the manifestation of the perfection already in man"; Swami Vivekananda reveals the progressive vision towards revamping education leads to nation. Knowledge is the gift of learning and is a goal of mankind. In a dynamic environment, students with different abilities, skills and backgrounds. Implementation of effective, creative and innovative teaching and learning methodologies will cater to the needs of the young minds. Until the inner teacher opens, all outside teaching is in vain. Conventional teaching in class room is a continuous process in same walls and boards. It will be bored or monotonous overtime. If more learning choices are given, learners take more ownership of their learning.

Ultimately academic mindsets, learning strategies and self-regulated learning behaviours will also developed (Steve Black and James D. Allen, 2017). They are necessary for meeting immediate goals and for lifelong learning. Optimized learning is more meaningful, relevant, leads to greater engagement and achievement. To encourage and enhance the learning behaviour of the students, use of technology plays a vital role.

Many higher educational institutions are embracing flipped learning, as it facilitates opportunities deeper understanding and increased student engagement with the use of technology (Goedhart, N.S., Blignaut-van Westrhenen, N., Moser, C. et al. Learning Environ Res 2019). This inverted learning approach gained popularity and is particularly well suited for technical education. To analyze and describe the current state of learning methodologies, few articles are reviewed for future research and development efforts.

Eric Mazur, Professor in Harvard University developed a model called Just In-Time teaching in 1990. He provided material for students in advance to prepare and reflect before class and then used class time to encourage deeper cognitive thinking via peer interaction and instructor challenge.

Activity based learning uses learner friendly educational tools and approaches. Activity based learning is focused to provide an environment for passive listeners to become active learners. It was started to use in India by British man David 
Horsburgh in 1944. Flipped learning is founded by Salman Kahn and is popularized in the early mid-2000s by the chemistry teachers Jon Bergman and Aaron Sams. This model was later expanded to include technological elements.

The presentation 'The Classroom Flip: Using Web Course Management Tools to Become a Guide by the side' (Baker 2000) emphasized the role of learning Management system to deliver materials to students before lecture hours. The role of teacher is articulated as facilitator and guide. Subsequent research focused on 'Inverting the classroom' as a means of providing an inclusive learning environment for personalized coaching and mentoring.

Flipped learning had not been evaluated as pedagogy in higher studies. but increase in attendance percentage, better grades and improvements in student and instructor interaction are emerging as greater numbers.

Measurable improvements in test scores were recorded when Physics class was flipped at Vanderbilt University in US. Large scale flipped learning was successfully implemented in 2012 at University of Queensland, Australia. University of Queensland is now leading among global universities. As an initiative in engineering education for better understanding and redesigning, flipped learning was adopted as best practice.

University of Manchester's Schools of Social Sciences and Computer Science have experimented with videos and tutorial sessions for flipped learning in small group work. Evaluation of this system suggested this flipped learning improved student engagement. This system highlighted the logistical challenges in implementing for small work groups within large cohorts.

Fast forward to present and dramatic growth of online content creation, collaboration and distribution tools provide practitioners with an accessible toolkit for delivering flipped learning. This paper provides an eagle eye view of proliferation of student-centered learning strategies. The rest of the paper is organized as follows: Section II describes conventional teaching strategies. Enhanced learning strategies are discussed in section III. Results and achieved objectives are presented in section IV which is followed by conclusion.

\section{CONVENTIONAL TEACHING STRATEGIES}

In conventional teaching system, each instructor has his/her own unique adopted style of teaching and the students have to adopt the technique to some extent. The students develop a tendency of selective studying. This results in a framed development of the thought process and reluctant behaviour of the student to bridge the knowledge gap. The instructor of the concerned subject arranges a tutorial class for breaking the conventional teaching process (William B. Wood, Kimberly D. Tanner, 2012). It is taken after completion of every chapter or module. This method not only gives them an exposure to different analogy based learning, but also motivates them for placement preparations.

\section{Lecturing}

The traditional most effective tool for teaching is lectures. Condensed vast material was delivered to the students. Lectures useful for the best listeners and meet the specific needs of thee audience. It is often argued by the educators that this conventional teaching method used repetition and memorization of information to educate the students. It may not provide enough skills for career opportunities in the field of technical education. Universities and other higher educational institutions recommend that effective learning strategies will influence the performance of the students for continuous lifelong learning.

\section{Teaching through Revealing}

View based instruction is one of the common teaching pedagogy followed in the classrooms. Usual teaching method focuses on collecting the views about the concepts from the students, sorting their views, finally concluding the session. This formal way of teaching must be focused towards course goals. During class room discussions, opportunity for open ended questions and debate to be offered. This training and learning strategy involves guidance to be given by the educators to accomplish the ideal learning. Any specific encouraging technique is to be fitting and effective; it must be in connection with the students and the kind of learning. These systems are focusing towards instruction which remains the students in the halfway of their understanding.

\section{INSTRUCTION AND EVALUATION}

The essential job of the educators is to pass the learning contents and data onto their understudies. In this strategy, instructing and assessing are seen as contiguous practices. Level of learning is assessed through written tests and evaluations. Any evaluations assume 'surprise test' will influence students' commitment in the course and instructors' conveyance of it. Indeed, even the unexpected test isn't amazement to the educator, who may have deliberately or generally arranged his class for it. An instructor has notoriety for conveying surprise test; the class may well plan for them in the 
event of some unforeseen issue.

Surprise test urges them to build up their insight, ability and disposition. This testing additionally helps them rationally arranged for semester examinations. This testing likewise helps the instructors and understudies to distinguish the problems of learning. Even this can be helped to improve the students thinking capability. This test can be considered as the review of the previous classes and even we can estimate the students understanding capacity.

\section{Visualization}

Face to face content delivery is inevitable for projects and practical experiments. Visualization is one of the successful strategies to bring visual and practical learning experiences. Prototype based learning is an effective way of learning methodology. For instance, if students are attending a computer hardware design class without knowing anything about the components and its purpose this leads to loss of interest and concentration in the subject and learners face lots of problem. And even they get bored instead of developing the interest in the subject.

In technical field, effective learning is not possible without visualizing the components. Due to the insufficiency of the components faculties prefer chalk and talk method which will lead to the improper understanding. To make it more comfortable, the teacher can make use of video presentation or prototype model of the component explanation before starting the class. But good result can be attained only by showing the original model of the component. The students will be able to visualize the parts and make use of it. Even these methods can be carried out with the practical classes so that the students can implement their own innovative skills in developing the new technology. Video lectures and computer assisted tools are effectively used for visualization based teaching techniques.

\section{ENHANCED LEARNING STRATEGIES}

For grooming the next generation, students should be empowered as learners. Learning will be optimized, if it is driven by interests. Learners are to be given a chance to take the ownership of learning. For greater involvement and lifelong achievement, innovative learning strategies and self-regulated learning behaviours are necessary. Interactive learning strategies using digital media for visualizing the ideas and concepts and recording their responses are more efficient and are needed to enhance the current education delivery system. These learning strategies are achieved through individual activities and group activities.

\section{Individual Learning Activities}

The framework for expanding learning environment for the students and the teachers include flexible, a learner centred approach, Intentional content. This maximizes the learning for the students and professional educators to upgrade continuously. This Individual learning activities include Flipped learning, Engage and Evaluate strategy and Polling Questions strategy.

\section{Flipped Learning}

Flipped learning is a blended learning approach done through technology. Pre recorded video contents or learning materials are introduced before class. To deepen the understanding in problem solving activities, discussion and interaction with peers is facilitated by teacher. This strategy enhances the traditional learning in a classroom context and facilitates to synthesize, analyze and evaluate afters the class (Gilboy M.B, Heinerichs S. Pazzaglia G, 2015).

The objectives of flipped learning are to motivate the students towards active learning and to engage in collaborative activity of peer learning (Abeysekera L and Dawson P. 2015). The role of teacher shifts himself or herself as facilitator for empowering the students to adopt their own way of learning. In flipped classroom, students acquire knowledge before the class. The environment and experience in the flipped learning is really different and highly appreciated (Steen-Utheim, A. T., \& Foldnes, N. 2018). They use the classroom time to practice and apply concepts and ideas through interaction with peers and teachers. Students reflect upon the received feedback and use it for further learning. Video creation and distribution tools provide the opportunity to create flipped content (Altemueller L, Lindquist C, 2017).

Flipped learning focus on efficient use of class time for accommodating different learners and engaging with problem based learning to improve the interaction between instructor and teacher and allowing students to take responsibility for learning (Arnold-Garza, S. 2014).

\section{Engage and Evaluate Strategy}


Multiple Choice Quizzes (MCQs) allow users to connect and can be accessed by a web interfaces. This Engage-Evaluate strategy is used for assessing the knowledge and understanding of the subjects. This formative assessment helps to break the traditional classroom activities. It helps the students to evaluate and understand their level of learning. It also leads to assess whether the knowledge is sufficient for completing assignments, or this will be useful to take a test etc. The learning level of the students are observed and confined. If there is long gap between assessment and understanding, lack of knowledge in subject and will be clarified with the professor during his or her lecture or the tutorials (Steve Black and James D. Allen, 2017).

\section{Polling Questions Strategy}

The students can gain knowledge by questioning. Critical thinking can also be stimulated by well crafted questions. They can poll questions, instruct their peers or get instructed by them. This questioning method initiates the gaining of deep subject knowledge. The students get motivated and get exposure to different analogy. By enforcing the questions as trainers, pros and cons of the topic can be analyzed and this helps the students to move with the different new innovative ideas. Questioning methodology makes the students to proceed with the right path throughout their career. Questioning by a teacher is a conventional practice. Question polling increases the higher order learning. Cognitive level of thinking for analyzing the information and concepts will also enhanced. The instructor will be the active member among the students for framing the questions. This methodology improves the questioning and briefing skills of the learners.

\section{GROUP LEARNING STRATEGIES}

Group learning is also termed as collaborative learning or cooperative learning. Group learning highlights the collaborative skills and high degree of responses. Group learning activities include pair and share strategy, inspire and initiate scenarios and connective thinking.

\section{Pair and Share Learning}

Pair and share is a collaborative learning strategy to maximize the student participation to find the solutions for their problems. The objectives of this strategy are individual thinking, Pair based on similarity in ideas; Share the ideas with the classmates. Discussion among partners enlarges the individual participation, focuses attention among peers and finally maximizing the student engagement. The Steps are: Designing a questionnaire, Pairing based on learning and understanding level and sharing their ideas among classmates.

\section{Inspire and Initiate Learning}

Inspire and initiate strategy entails personalized learning. Outside the class room, learners are informed to learn video lectures or online learning materials about the subject. Through smart electronic devices or in class, learners or asked to participate in active learning discussions. It initiates learning the best, gets inspired, and motivates the others to learn the right thing, at right time, in the right medium and at right pace. It is connected with learner's preferences, background, approach and experiences.

\section{Connective Thinking}

Generally, mind works in analogies, connects different thoughts and concepts that new ideas are born. Connective thinking gives a connective environment. In this type of learning strategy, the ideas can be collected from a group or from the outside world and it can be connected with one another to form a new idea. Single person thoughts and ideas would be ideal from one another so those ideas can be merged and can be formed into a new innovative technique. When a topic is discussed in a class, learners would have relevant or irrelevant perception about the topic. The instructor can gather those perceptions to estimate the understanding level of the learners. With this level of thinking, learners can be formed into a group and they can implement their ideas in developing innovative techniques.

\section{E-LEARNING}

E-Learning is simply accessing the learning resources anywhere, anytime learning through electronic devices and technologies. Outside the classroom, E-learning is facilitated as courses delivered to learners through internet. It may include pre recorded sessions or interactive sessions. E-Learning is proven to be effective technique for teaching and learning.

E-Learning is comprised of group of learners and not for everyone. They are expected to be self discipline to work through the materials regularly. There are scheduled assignments and tests that must be submitted on time. E-Learning is a good 
choice for the students who are having time management skills. All the institutions are initiated to participate in the ELearning program. Necessary hardware and software are the basic requirements to get involved in the online courses. Effective time management and planning schedule ensure to reach the goals of learning.

\section{M-LEARNING}

Mobile learning, shortly M-Learning is an enhanced version of E-Learning. It becomes primary conduit in learning through personal electronic devices such as mobile phones/smart phones, iPads, Laptops and Tablet PCs. The widespread availability broad band technology and smart phones are the key platforms for enhancing the student learning system. While conceptualizing the methodologies, widespread availability of the smart phones replaced conventional and even computer based teaching. Smart phone based learning has converged many features and digital tools.

Unlike flipped learning, the asynchronous way is enhanced by interacting with peer groups and experts for clarification of concepts and doubts which leads to the next level of learning. Higher education institutions and even schools are using various educational apps and M-Learning techniques. Learners and trainers are motivated to learn new. Synchronous learning is possible, immediate and direct feedback is given by the instructor to the learners.

M-Learning is an effective methodology to the $21^{\text {st }}$ century students. Continuous learning is supported by mobile devices. It is also designed to integrate formative assessment and scoring. Learning materials with videos, audio files and images make learning system more interesting and interactive. Application of learning techniques must be the preferred mode for students.

Mobile games have always been the favourite past time for people of all age groups. Game based learning refers games as a mechanism for learning specific concepts. All the interactive learning strategies can also be implemented as M-Learning techniques. Learners are encouraged to be aware of their learning strengths and weaknesses. Learners must be self discipline and more focused to avoid distractions and notifications. When they are finding very difficult to complete their assigned learning process, they can develop their own strategies to overcome the challenges. Additionally, lack of electricity and internet connection are the major technical issues. While considering all these issues related with MLearning, the achieved learning objectives proliferates as the compromised solutions.

\section{RESULTS}

The performance and success of learning strategies are analyzed by level of acceptance and objectives. Though there are many effective strategies, pros and cons of the system must be investigated. With the use of right technology and tools, Learning receives immediate feedback and understanding level through formative assessment immediately to the teacher. In education system, the use of technology has removed the barriers in teaching and learning. It is useful for crossing the educational boundaries for both teachers and students. It enriches and promotes essential skills for millennial culture. MLearning provides tremendous flexibility to choose their devices and time to learn. The objectives of the learning are achieved highly through enhanced learning strategies which are:

- Just-In time Learning

- $\quad$ Personalized Learning

- Engages students in learning

- Enhances their Self confidence

- Promotes Cooperative learning

- Efficient for large training groups

- Enlighten Critical problem solving

- Develop communication among peers

- Encourages the high degree of responses

- Reduction of cultural and communication barriers

\section{CONCLUSION}

Activity based learning enhances the students learning preferences. The advantages of activity based learning are retaining the interest and attention throughout the learning process. All the recommended individual and group activities can also be done portably by smart phone based m-learning. It initiates the learning process by viewing and uploading relevant lectures, audio clips and videos. We hope that that any of the learning strategies cannot be underestimated. All learners have different preferences and experiences. Success of these learning strategies depends on learners' level of acceptance and achievement. 


\section{REFERENCES}

1. Abeysekera L and Dawson P. (2015). Motivation and cognitive load in the flipped classroom: Definition, rationale and a call for research. Higher Education Research \& Development, 34(1), 1-14.

2. Altemueller, L., \& Lindquist, C. (2017). Flipped classroom instruction for inclusive learning. British Journal Of Special Education, 44(3), 341-358. doi:10.1111/1467-8578.12177.

3. Arnold-Garza, S. (2014), The Flipped Classroom Teaching Model and its use for Information Literacy Instruction, 8 (1). http://files.eric.ed.gov/fulltext/EJ1089137.pdf.

4. Gilboy M.B, Heinerichs S., Pazzaglia G., (2015), Enhancing Student Engagement Using the Flipped Classroom, Journal of Nutrition Education and Behaviour, Vol. 47 (1), 109-114. https://doi.org/10.1016/j.jneb.2014.08.008.

5. Goedhart, N.S., Blignaut-van Westrhenen, N., Moser, C. et al. Learning Environ Res (2019) $22: 297$. https://doi.org/10.1007/s10984-019-09281-2.

6. Steve Black and James D. Allen. (2017). Insights from Educational Psychology Part 2: Goals, Mindset, and SelfRegulation, Reference Librarian, 58(2), 159-173. doi:10.1080/02763877.2016.1221787.

7. Steen-Utheim, A. T., \& Foldnes, N. (2018). A qualitative investigation of student engagement in a flipped classroom. Teaching in Higher Education, 23(3), 307. https://doi.org/10.1080/13562517.2017.1379481

8. William B. Wood, Kimberly D. Tanner.(2012),CBE Life Sci Educ. 2012 Spring; 11(1): 3-9. Https://doi: 10.1187/cbe.11-12-0110PMC3292071. 